\title{
LUNG VOLUMES AND MECHANICS OF BREATHING IN TETRAPLEGICS
}

\author{
By J. V. Forner, M.D., D.Phys.Med.(Lond.) \\ Department of Physical Medicine and Rehabilitation, Ciudad Sanitaria \\ 'La Fe' de Valencia, Spain
}

\begin{abstract}
The purpose of this study was to investigate the influence of the paralysis of some respiratory muscles, due to a spinal cord lesion, on the lung volumes and the mechanics of breathing, specially on the maximal expiratory flows. Fifty-two tetraplegics have been studied, divided in two groups-according to the level of the lesion to investigate if there is any difference in the behaviour of both groups.
\end{abstract}

Key words: Respiratory muscle paralysis; Flow-volume curve; Lung volumes; Respiratory problems; Tetraplegia.

\section{Introduction}

TETRAPLEGICS suffer from paralysis of some inspiratory and most of the expiratory muscles. The diaphragm, that is the main inspiratory muscle, is spared in lesions below $\mathrm{C}_{5}$ but at this level all expiratory muscles are paralysed. This has very deleterious effects on the ventilatory function of the lungs, especially in the early stages when the mortality rate, due to respiratory problems, is very high, ranging from 7.4 to 40 per cent (Durbin, I957; Norton, I962; Tribe, 1963; Cheshire, I964; Cheshire \& Coats, 1966; Guttmann \& Frankel, I966; Silver \& Gibbon, I968; Bellamy et al., I973).

The risk of atelectasia and pneumonia after respiratory infections is also higher throughout their life due to difficulty in eliminating bronchial secretions.

Nevertheless many patients can readapt the function of the auxiliary respiratory muscles and compensate satisfactorily their disability (Guttmann \& Silver, 1965; Guttmann, 1976).

We have studied the effects of the cervical spinal cord lesion on some parameters of the ventilatory function and the differences found between two groups of patients according to the level of the lesion.

\section{Material and Methods}

Fifty-two traumatic tetraplegic patients have been investigated. They had been admitted to the National Paraplegic Centre at Toledo ( 32 cases) and to the Spinal Unit of ' $\mathrm{La} \mathrm{Fe'} \mathrm{Hospital} \mathrm{at} \mathrm{Valencia} \mathrm{(20} \mathrm{cases).}$

There were 46 males and six females of ages ranging between $\mathrm{I} 6$ and $6 \mathrm{I}$, the mean age being 33.3 years. Twenty-five of them were smokers but all were free from any respiratory disturbance at the time of the examination although during the acute stage thirteen of them had a tracheostomy done due to respiratory insufficiency (Table I). In 42 cases the spinal cord lesion was complete and in the ten remaining cases some sacral sparing was present although no voluntary muscle activity was detected below the lesion.

The patients were divided into two groups according to the level of lesion, 
TABLE I

\begin{tabular}{cccc}
\hline Level & No. of patients & Smoker & Tracheostomy \\
\hline C5 & I I & I & 2 \\
C6 & I5 & 7 & 2 \\
C7 & 22 & I5 & 8 \\
C8 & 4 & 2 & I \\
Total & 52 & 25 & I3 \\
\hline \multicolumn{4}{c}{ Mean age $=33.2 \pm 10.5 \%$}
\end{tabular}

including in the group I, I I patients with lesions below $\mathrm{C}_{5}$ and I $_{5}$ patients with lesions below C6. In group II were included 22 patients with lesions balow $\mathrm{C}_{7}$ and four patients with lesions below C8. All measurements were performed in the sitting position and without corset or abdominal belt.

During the first day a standard spirometry was performed in a I3-litre waterfilled spirometer (Volumograph: Mijnhardt) discarding the patients who did not co-operate adequately.

To obtain the flow-volume curves, the patients performed a Forced Vital Capacity manoeuvre through a Jaeger pneumotachograph. The curves were recorded in a Hewlet Packard direct writing recorder. Normal values of the peak expiratory Flow (PEF) and the maximal expiratory flow (MEF) at 75, 50 and 25 per cent of the Vital Capacity were taken from Cherniack and Raber (I972).

The static pressure-volume curves were obtained by the flow interruption method measuring the intrathoracic pressure with a balloon inserted in the middle third of the oesophagus according to the method of Milic-Emili (1964). The transpulmonary pressure was the difference between the oesophagic pressure and the mouth pressure obtained through a differential transductor.

In order to assess gas distribution and closing volumes, single breath $\mathrm{N}_{2}$ washout curves were performed in the standard manner (Buist \& Ross, 1973).

\section{Lung volumes}

\section{Results}

Table II shows the mean values of the lung volumes in the 52 patients and in each group into which we have divided them.

The mean value of the Total Lung Capacity (TLC) was moderately decreased on the whole group ( $74 \pm 13$ per cent). It was found normal in five patients of group I and I 3 patients of group II.

The Vital Capacity (VC) was reduced to a half of the normal predicted values ( $5 \mathrm{I} \pm \mathrm{I} 6$ per cent). It was normal in only three patients of group II.

The Expiratory Reserve Volume (ERV) was reduced to a third of the normal predicted $(33 \cdot 8 \pm 21$ per cent). It was found normal in only two patients of group II. In the above mentioned parameters the difference between both groups of patients was found significant. The Functional Residual Capacity was slightly decreased $(78 \cdot 8 \pm 18$ per cent) on the whole group and the difference between both groups of patients was not significant. It was found normal in I I patients of group I and I3 patients of group II. The Residual Volume (RV) showed an overall increase to $132 \cdot 3 \pm 39$ per cent and the difference between both groups of patients was not significant. It was found normal in eight patients of group I and 12 of group II. 
TABLE II

\begin{tabular}{|c|c|c|c|c|c|c|}
\hline Level & & $\%$ TLC & $\% \mathrm{VC}$ & $\%$ ERV & $\%$ FRC & $\% \mathrm{RV}$ \\
\hline $\mathrm{n}=26$ & $\overline{\mathrm{X}}$ & 70 & $43 \cdot 5$ & $23 \cdot 8$ & $78 \cdot 5$ & $\mathrm{I} 4 \mathrm{I} \cdot 5$ \\
\hline $\mathrm{C}_{5}-6$ & SD & $12 \cdot 6$ & $13 \cdot 8$ & $16 \cdot 4$ & $2 I \cdot 8$ & 42 \\
\hline $\begin{array}{c}n=26 \\
\text { II }\end{array}$ & $\overline{\mathrm{X}}$ & 78 & $58 \cdot 3$ & $43 \cdot 9$ & 79 & $I 23 \cdot I$ \\
\hline \multirow[t]{2}{*}{$\mathrm{C}_{7-8}$} & SD & II $\cdot 7$ & $15 \cdot 8$ & $20 \cdot 5$ & $13 \cdot 7$ & $34 \cdot 5$ \\
\hline & $\mathrm{P}$ & $\star$ & $\star \star \star$ & $\star \star \star$ & NS & NS \\
\hline $\mathrm{n}=52$ & $\overline{\mathrm{X}}$ & 74 & $50 \cdot 9$ & $33 \cdot 8$ & $78 \cdot 8$ & $132 \cdot 3$ \\
\hline Total & SD & $12 \cdot 7$ & $16 \cdot 5$ & $2 \mathrm{I}$ & I 8 & $39 \cdot 2$ \\
\hline
\end{tabular}

\section{Mechanics of Breathing}

As we see in Table III the Forced Expired Volume in I second $\left(\mathrm{FEV}_{1}\right)$ was reduced in absolute value $(52 \cdot 6 \pm \mathrm{I} 7$ per cent), being the significant difference between both groups of patients. Nevertheless this value was normal if expressed as a percentage of the FVC.

Table IV shows the mean values of flows.

The Maximal Mid-Expiratory Flow rate $(M M E F)$ was reduced to $(60 \pm 29$ per cent) but while almost normal in the patients of group II ( $77 \pm 26$ per cent) it was greatly reduced in the patients of group I ( $39 \pm$ I 5 per cent).

\section{TABLE III}

\begin{tabular}{|c|c|c|c|c|}
\hline Level & & $\mathrm{FEV}_{1}$ & $\% \mathrm{FEV}_{1}$ & $\begin{array}{l}\text { Tiffeneau } \\
\text { Index }\end{array}$ \\
\hline $\begin{array}{c}\mathrm{n}=26 \\
\mathrm{I} \\
\mathrm{C} 5-6\end{array}$ & $\begin{array}{l}\bar{X} \\
\text { SD } \\
\text { SE }\end{array}$ & $\begin{array}{l}I \cdot 7 \\
0 \cdot 6 \\
O \cdot I\end{array}$ & $\begin{array}{r}45 \cdot 2 \\
\text { I } 3 \cdot 9 \\
2 \cdot 7\end{array}$ & $\begin{array}{c}83 \cdot 3 \\
9 \\
1 \cdot 8\end{array}$ \\
\hline$\underset{\substack{\text { II } \\
C_{7}-8}}{26}$ & $\begin{array}{l}\bar{X} \\
\text { SD } \\
\text { SE }\end{array}$ & $\begin{array}{l}2 \cdot 2 \\
0.6 \\
0 \cdot 1\end{array}$ & $\begin{array}{l}60 \\
17 \cdot 7 \\
3.5\end{array}$ & $\begin{array}{r}8 \mathrm{I} \cdot 3 \\
9 \cdot 8 \\
\mathrm{I} \cdot 9\end{array}$ \\
\hline & $\begin{array}{l}\mathrm{t} \\
\mathrm{p}\end{array}$ & $\underset{\star \star}{2 \cdot 9240}$ & $3 \cdot \underset{\star \star}{3679}$ & $\begin{array}{c}0.753^{2} \\
\mathrm{NS}\end{array}$ \\
\hline $\mathrm{n}=52$ & $\begin{array}{c}\bar{X} \\
S D\end{array}$ & $\begin{array}{l}2 \\
0 \cdot 7\end{array}$ & $\begin{array}{l}52 \cdot 6 \\
17 \cdot 5\end{array}$ & $\begin{array}{r}82 \cdot 3 \\
9 \cdot 4\end{array}$ \\
\hline Total & SE & $O \cdot I$ & $2 \cdot 4$ & $I \cdot 3$ \\
\hline
\end{tabular}

$\overline{\mathrm{X}}=$ Media $\quad \mathrm{SD}=$ Standard Deviation $\quad \mathrm{SE}=$ Standard Error 
TABLE IV

\begin{tabular}{|c|c|c|c|c|c|c|}
\hline Level & & $\% \mathrm{PEF}$ & $\% \mathrm{MEF}_{75}$ & $\% \mathrm{MEF}_{50}$ & $\% \mathrm{MEF}_{25}$ & $\%$ MMEF \\
\hline$n=I 5$ & $\overline{\mathrm{X}}$ & $40 \cdot 9$ & $42 \cdot 3$ & $38 \cdot 7$ & $36 \cdot 4$ & $39 \cdot 2$ \\
\hline $\mathrm{C}_{5}-6$ & SD & I $4 \cdot 7$ & 14.9 & $\mathrm{I} 2 \cdot 2$ & 13.8 & $15 \cdot 3$ \\
\hline$n=15$ & $\overline{\mathrm{X}}$ & $53 \cdot 5$ & 57 & $57 \cdot 5$ & $60 \cdot 4$ & $77 \cdot 5$ \\
\hline \multirow[t]{2}{*}{$\mathrm{C}_{7-8}$} & SD & $18 \cdot 9$ & $2 I \cdot 2$ & $22 \cdot 9$ & $28 \cdot 6$ & $25 \cdot 9$ \\
\hline & $P$ & NS & $\star$ & $\star \star$ & $\star \star$ & $\star \star$ \\
\hline $\mathrm{n}=30$ & $\overline{\mathrm{X}}$ & $47 \cdot 2$ & $49 \cdot 7$ & $48 \cdot I$ & $48 \cdot 4$ & $60 \cdot 3$ \\
\hline Total & SD & $17 \cdot 8$ & 19.5 & $20 \cdot 4$ & $25 \cdot 2$ & $28 \cdot 9$ \\
\hline
\end{tabular}

The mean values of the Peak Expiratory Flow (PEF) and Maximal Expiratory Flows at 25, 50 and 75 per cent of the VC were reduced to approximately half of the normal predicted values according to Cherniack et al. (I972).

Excluding the PEF the flow reduction was significantly higher in the patients of group I than in the patients of group II.

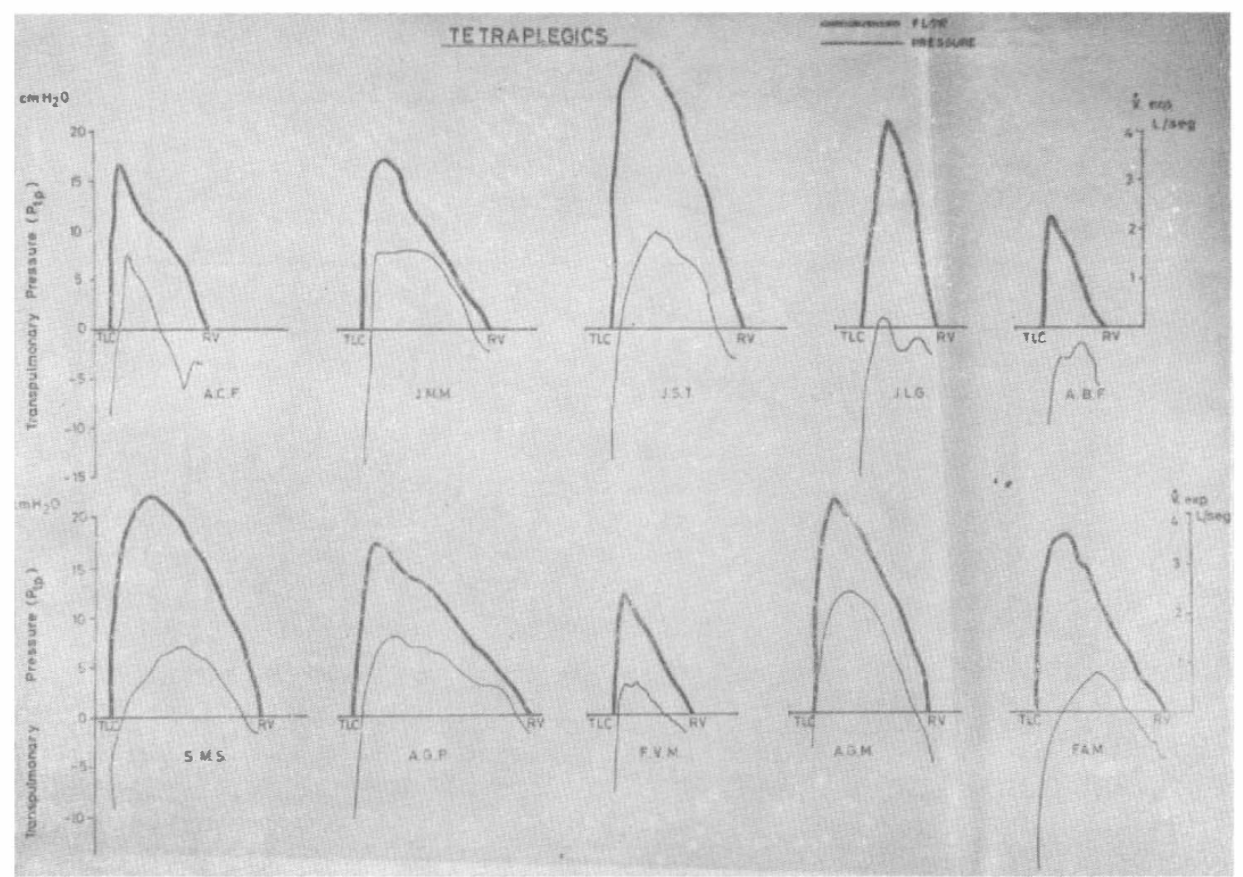

FIG. I

The flows and transpulmonary pressures are plotted in ro patients. In the patient A.B.F. the transpulmonary pressure was always negative. 
The transpulmonary pressure $\left(P_{t p}\right)$ was measured in ten patients during the performance of a FVC manoeuvre and it was found greatly reduced in all of them, never exceeding $12.5 \mathrm{~cm}$ of $\mathrm{H}_{2} \mathrm{O}$ in contrast with normal subjects that may reach the $100 \mathrm{~cm}$ of $\mathrm{H}_{2} \mathrm{O}$. In one case the $\mathrm{P}_{\mathrm{tp}}$ was negative throughout the FVC manoeuvre (Fig. I).

TABLE V

\begin{tabular}{|c|c|c|c|}
\hline Level & & $\mathrm{Cst} / \mathrm{I} \mathrm{cm} \cdot \mathrm{H}_{2} \mathrm{O}$ & $\begin{array}{l}\text { Pst (I) } \max \\
\mathrm{cm} \cdot \mathrm{H}_{2} \mathrm{O}\end{array}$ \\
\hline $\mathrm{n}=8$ & $\overline{\mathrm{X}}$ & $0 \cdot 167$ & I $8 \cdot 8$ \\
\hline$C_{5}-6$ & SD & 0.04 & $5 \cdot 6$ \\
\hline $\mathrm{n}=\underset{\text { II }}{=} \mathrm{II}$ & $\overline{\mathrm{X}}$ & 0.206 & $20 \cdot 9$ \\
\hline \multirow[t]{2}{*}{$\mathrm{C}_{7-8}$} & SD & 0.08 & $5 \cdot I$ \\
\hline & $\mathrm{p}$ & NS & NS \\
\hline $\mathrm{n}=\mathrm{I} 9$ & $\overline{\mathrm{X}}$ & $0 \cdot 190$ & $20 \cdot 0$ \\
\hline Total & SD & 0.07 & $5 \cdot 3$ \\
\hline
\end{tabular}

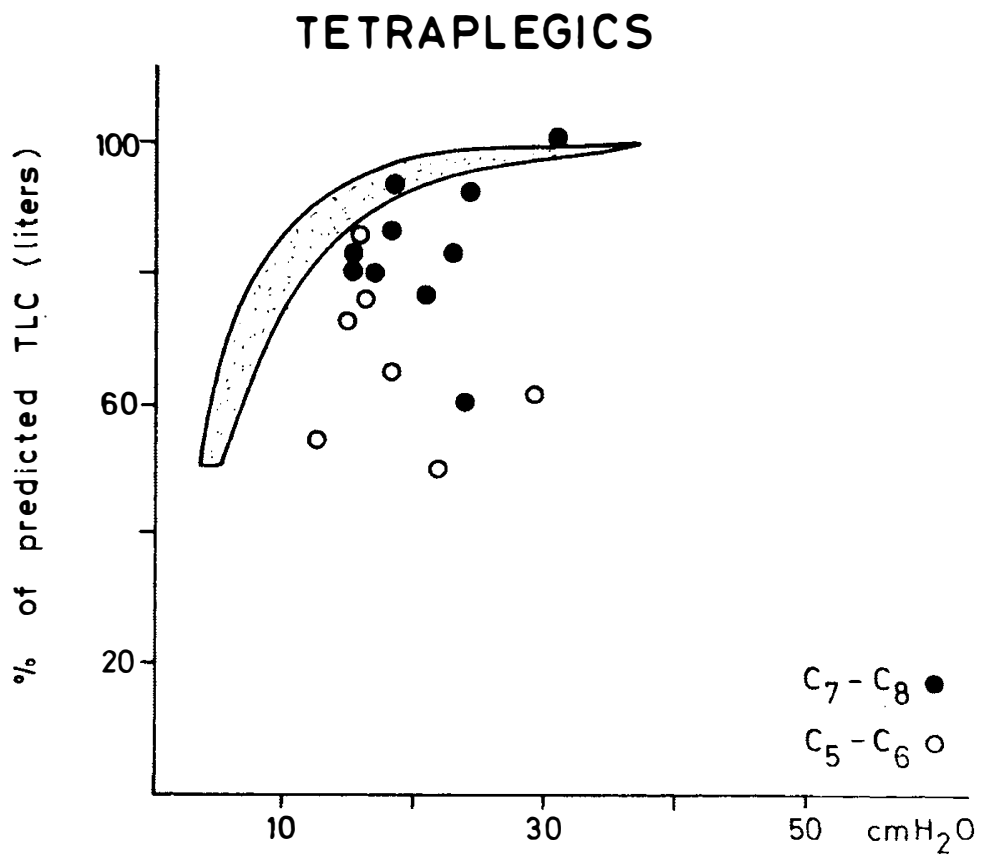

FIG. 2

The static recoil pressure (Pst) of our patients. The shadowed area is the normal Pst. 
The Static Compliance $\left(\mathrm{C}_{\mathrm{st}}\right)$ was measured in 19 patients and was found moderately decreased in nine patients and normal in the rest. The mean value was within normal limits $\left(0 \cdot 190 \pm 0.07 / 1 \mathrm{~cm} \mathrm{H}_{2} \mathrm{O}\right)$ (Table V).

The static recoil pressure (Pst) at TLC was measured in 17 cases and was found reduced in 15 of them. Nevertheless as the TLC was also reduced, the Pst of most of the patients was higher than in normal subjects at the same lung volume (Fig. 2).

The single breath $\mathrm{N}_{2}$ wash out curves were performed in 19 patients. The phase III was slightly abnormal in seven cases and normal in the rest showing that gas distribution was not grossly abnormal in these patients.

However a constant finding was the absence of a closing volume (phase IV). Nevertheless if at the end of the expiration, a gentle manual pressure was applied on the abdomen, the closing volume became readily apparent (Fig. 3).

\section{TETRAPLEGICS}
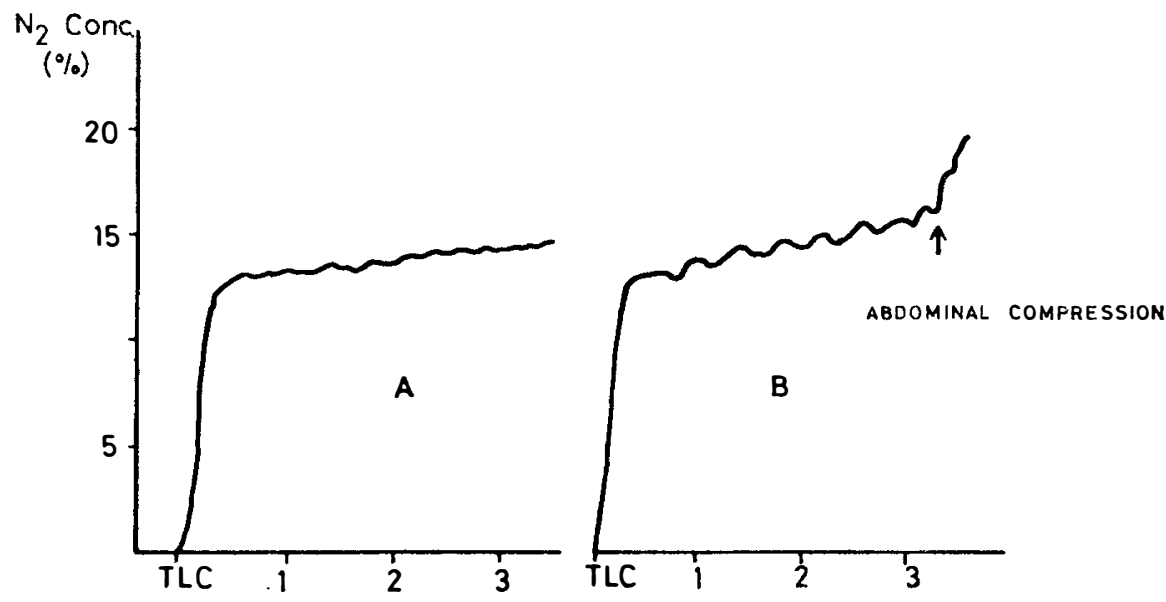

VOLUME

LITRES

FIG. 3

Single breath $\mathrm{N}_{2}$ wash out curves.

\section{Discussion}

The alterations observed in the lung volumes are in keeping with the results observed by previous authors (Cameron et al., 1955; Hemingway et al., 1958; Grossiord et al., 1963; Stone \& Keltz, 1963; Bergofsky, 1964; Haas et al., I965; McKinley et al., 1969; Fugl-Meyer, 1971; Gibson et al., 1977; Kreitzer et al., I978; Forner et al., 1978). factors.

The slight reduction in TLC may be due to one or more of the following

(a) Paralysis of the auxiliary inspiratory muscles that are active in the last degrees of chest expansion. 
(b) Paralysis of the intercostals allowing some 'suction' of the intercostal spaces during inspiration.

(c) Spasticity of the abdominal muscles that would prevent the diaphragmatic descent.

(d) (Rigidity of the thoracic cage joints.) Decreased range of motion of cortovertebral joint that would diminish the complete chest expansion.

(e) A reduction in the lung compliance that was present in some of our patients.

The decreased VC found in our patients is partly due to the reduction in inspiratory capacity but mainly to the low ERV. The FRC does not show great modifications in these subjects as it just represents a position of equilibrium between ribcage and lung parenchyma. The important decrease in the ERV is due to the paralysis of most of the expiratory muscles. The patients of group II with lower lesions show a higher ERV due to the action of the latissimus dorsi and other muscles of shoulder girdle that may act as expiratory (Grossiord et al., I963). The reduction in the ERV explains the increased RV as no airway obstruction was found in our patients. The relation FEVI/FVC was normal, indicating the absence of airway obstruction although in some cases the test was difficult to carry out due to spasms of the abdominal muscles.

Regarding the Forced Expiratory Flows we have plotted the real curves together with the theoretical ones taking into account the reduction of the VC and TLC and the increase in $\mathrm{RV}$.

The behaviour was not uniform, being able to differentiatefour types of curves:

(a) Normal: the three cases (Nos. 29, 30, 3I) from group II could be considered normal.

(b) Obstructive: three cases from group I and three cases from group II (Nos. $2,12,21,28,32,48)$ show the morphology found in obstructive disease of small airways.

(c) Restrictive: in three cases of group I and seven cases of group II (cases I3, I $4,15,27,34,35,36,37,47,49$ ) the volumes were reduced but the flows were normal at the lung volumes considered.

(d) In nine cases of group I and two patients of group II (cases I, IO, I I, I6, $17,18,19,20,25,33,50)$ the lung volumes were reduced and also the flows even in the portion of the curve in which the flows are independent of the effort.

In these cases there was not detected any increase in the resistance of airways or in the compliance to explain the reduction of flows. The only explanation is a marked reduction in transpulmonary pressure during the forced expiratory manoeuvre that would be insufficient to achieve the critical flows necessary to render them effort independent.

Another consequence of the reduced pleural pressure would be the absence of a demonstrable phase IV in the $\mathrm{N}_{2}$ wash-out curve. Cessation of flow would be rather abrupt in all lung units without the sequential closure of airways because the pleural pressure was negative. When it was increased by abdominal compression a closing volume appeared readily.

The observed reduction in static compliance in some cases also found by Stone and Keltz (1963) and Bergofsky (1964) could be due to microatelectasis or altered surfactant probably produced by the lack of sighing or repeated infections in the acute stages (Montero et al., 1967).

Nevertheless we have found that in many cases mainly from group II, the expiratory flows were higher than expected considering the paralysis of most expiratory muscles. These patients can manage to achieve adequate transpulmonary pressures by means of adequate contractions of the muscles of the neck 
that raise the ribcage storing energy for the expiration or by tilting the body forward to raise the abdominal pressure. The co-ordinate contraction of latissimus dorsi and pectoralis major could be an adequate expiratory force (Grossiord et al., 1963) especially if the arms are fixed.

\section{SUMMARY}

The paralysis of the respiratory muscles in cervical patients, which affects mainly the expiratory muscles, produces an important reduction of the TLC, VC, and ERV. The RV is increased.

The Maximum Expiratory Flows are reduced in many cases, at any lung volume considered, due to the fact that the transpulmonary pressure is lower than the critical pressure necessary to make flows effort independent.

In other cases the compensatory mechanisms, consisting of elevation of rib cage, tilting the trunk forward and co-ordinate contraction of latissimus dorsi and pectoralis major, are very efficient.

\section{RÉSUMÉ}

La paralysie des muscles respiratoires à niveau cervical qui atteint principalement aux muscles expiratoires donne place à une importante diminution de la TLC, VC et surtout du ERV. Le RV s'est augmenté.

Les débits expiratoires maximes sont diminués en plusieurs cas, quelconque volume pulmonaire que ça soit, due au fait que la pression transpulmonaire résultant est inférieur à la critique.

Dans d'autres cas les mécanismes qui compensent; élévation du thorax, indication du tronc en avant et la contraction du latissimus dorsi et pectoralis major sont très efficaces.

\section{ZUSAMMENFASSUNG}

Die respiratorische Muskellähmung in zervikalen Lähmungen, welche hauptsächlich expiratorische Muskeln betrifft, verursacht einen wichtigen Ausfall der TLC, VC und hauptsächlich der ERV. Der RV ist erhöht.

Die maximalen expiratorischen Flows sind in vielen Fällen vermindert. Das ist unabhängig von Lungvolumen, da der transpulmonale Druck kleiner ist als der kritische Druck. Es ist notwendig, den pulmonalen Flow unabhängig von der Arbeitskraft der Muskulatur zu machen.

In anderen Fällen bestehen die kompensatorischen Massnahmen aus: (a) Erhöhung des Brustkorbes; (b) Beugung nach vorne; (c) Spannung des M. latissimus dorsi und $M$. pectoralis major.

\section{REFERENCES}

Bellamy, R., Pitts, F. W. \& Stauffer, E. S. (1973). Respiratory complications in traumatic quadriplegia. F. Neurosurg., 39, 5, 596-600.

BERGOFSKY, E. H. (I964). Mechanism for respiratory insufficiency after cervical cord injury. A source of alveolar hypoventilation. Ann Intern. Med., 6I, 435-447.

Buist, A. S. \& Ross, B. B. (1973). Predicted values for closing volumes using a modified single breath nitrogen test. Amer. Rev. Resp. Dis., 107, 744-752.

CAmeron, G. S., ScotT, J. W., Jousse, A. T. \& BotTerell, E. H. (I955). Diaphragmatic respiration in the quadriplegia patient and the effect of position on his vital capacity. Annals of Surgery, 141, 4, 45I-456.

Cheshire, D. J. E. (I964). Respiratory management in acute traumatic tetraplegia. Paraplegia, I, 4, 252-261.

Cheshire, D. J. E. \& CoATs, D. A. (I966). Respiratory and metabolic management in acute tetraplegia. Paraplegia, 4, I, I-23. 
CHERNIACK, R. M. \& RABER, M. B. (I972). Normal standards for ventilatory function using an automated wedge spirometer. Amer. Rev. Resp. Dis., 106, 38-46.

Durbin, F. C. (I957). Fracture-dislocation of the cervical spine. F. Bone and foint Surg. 39B, 23-38.

ForNer Valero, J. V., Llopis Llombart, R. \& Valdizan Valledor, M. C. (1978). The flow volume loop in tetraplegics. Paraplegia, 15, 245-25I.

FUGL-MeYeR, A. R. (I97I). Effects of respiratory muscle paralysis in tetraplegic and paraplegic patients. Scand. F. Rehab. Med., 3, I4I-I 50.

Gibson, G. J., Pride, N. B., Newsom Davis, J. \& LoH, L. C. (I957). Pulmonary mechanics in patients with respiratory muscle weakness. Amer. Rev. Res. Dis., II 5, 389-395.

Grossiord, A., Jaeger-Denavit, Mme. O. \& ANA M Miranda, G. (I963). Contribution à l'étude des troubles ventilatoires des para- et tétraplégiques. La Semaine des Hôpitaux, I5, pp. 663-676.

GutTMANN, L. \& Frankel, H. (1966). The value of intermittent catheterisation in the early management of traumatic paraplegia and tetraplegia. Paraplegia, 4, 2, 63-83.

GutTMANN, L. \& SilveR, J. R. (1965). Electromyographic studies on reflex activity of the intercostal and abdominal muscles in cervical cord lesions. Paraplegia, 3, I-22.

Guttmann, SIR Ludwig. (1976). Spinal cord injuries. Comprehensive management and research. Blackwell Scientific Publications. 2nd edition.

HAAS, A., Lowman, E. W. \& BERGOFSKY, E. H. (I965). Impairment of respiration after spinal cord injury. Arch. Phys. Med., 46, 399-405.

Hemingway, A., Bors, E. \& Hobby, R. P. (I958). An investigation of the pulmonary function of tetraplegics. $\mathcal{F}$. Clin. Investig., 37, 773-782.

Kreitzer, S. M., SAUNDERS, N. A., TyleR, H. R. \& INGRAM, R. H. Jr. (1978). Respiratory muscle function in amyotrophic-lateral sclerosis. Am. Rev. Respir. Dis., II7, 437447.

Milic-Emili, J., Mead, J., Turner, J. M. \& Glauser, E. M. (I964). Improved technique for estimating pleural pressure from esophageal balloons. F. Appl. Physiol., 19, 2072 II.

McKinley, A. C., Auchincloss, J. H. Jr., Gilbert, R. \& Nicholas, J. J. (I969). Pulmonary function, ventilatory control and respiratory complications in quadriplegic subjects. Amer. Rev. Resp. Dis., 100, 526-532.

Montero, J. C., Feldman, D. L. \& MonTERo, D. (I967). Effects of glossopharyngeal breathing on respiratory function after cervical cord transection. Arch. Phys. Med., 48, $650-653$.

Norton, W. L. (1962). Fractures and dislocations of the cervical spine. F. Bone and foint Surg., 44A, I I 5-I 39 .

Silver, J. R. \& Gibbon, N. O. K. (1968). Prognosis in tetraplegia. Brit. Med. F., 2, 79-83.

StoNE, D. J. \& KelTZ, H. (I963). The effect of respiratory muscle dysfunction on pulmonary function. Studies in patients with spinal cord injuries.

TRIBE, C. R. (I963). Causes of death in the early and late stages of paraplegia. Paraplegia, I, $19-46$. 